\title{
Late onset Krabbe's leukodystrophy: a report of four cases
}

\author{
Megan Phelps, Jean Aicardi, Marie-Thérèse Vanier
}

\begin{abstract}
Four cases of late-onset Krabbe's leukodystrophy had varying clinical features. One sibling became wheelchair-bound while another leads an active working life. The computed tomography (CT) scan of a third patient showed occipital demyelination with contrast enhancement identical to that seen in an adrenoleucodystrophy. The fourth was the only patient with peripheral neuropathy. All patients had enzyme activity comparable to the classic infantile-onset form.
\end{abstract}

Globoid cell leukodystrophy was originally described in 1916 by Krabbe as a familial infantile form of diffuse brain sclerosis, with a late onset form also described. With the establishment of the enzyme deficiency (galactosylceramidase) in 1970 by Suzuki and Suzuki ${ }^{1}$ the diagnosis may be confirmed by determining enzyme activity as well as the histopathology. Among the approximately 200 cases of Krabbe's leukodystrophy described in the literature we know of 19 cases of enzymatically proven late-onset Krabbe's leukodystrophy.

The heterogeneity of the clinical presentation and the investigational profile of the late onset form of Krabbe's leukodystrophy is becoming more apparent. The presenting symptoms may include difficulty in walking, decreased visual acuity, irritability and other behavioural changes. Investigation in the late onset form may reveal abnormal cerebral CT scan, abnormal visual evoked responses and slowed nerve conduction velocities, normal or slightly elevated CSF protein and characteristic inclusions in nerve and skin biopsies. These may be present in almost any combination.

Five families with siblings that have been affected have been observed in the literature. ${ }^{23}$ Loonen $^{2}$ has described 17 cases from the literature and one additional case, but it appears that the descriptions of Crome et $a l^{4}$ and Hanefeld et $a l^{5}$ are the same three cases. Our study describes four patients with enzymatically proven late-onset Krabbe's leukodystrophy, and includes a brother and sister. The striking difference in clinical features between two siblings with the late onset form has not, to our knowledge, been reported.

\section{Patients and methods}

Four cases of late onset Krabbe's leukodystrophy were seen in the neurology unit of the Hôpital des Enfants Malades (Paris) between June 1984 and November 1988. Between November 1979 and November 1989 six cases of the classic infantile form were identified, making a total of ten cases of Krabbe's leukodystrophy.

Leucocytes and skin fibroblast cultures were obtained according to standard procedures. Total homogenates, prepared as previously described, ${ }^{6}$ served as the enzyme source. $(3 \mathrm{H}-$ 6 -galactose)-Galactosylceramide $(500 \mathrm{~Bq} /$ nmol) with nevronic acid as the uniform fatty acid $^{7}$ was provided by Professor Lars Svennerholm and Docent Jan-Eric Mansson, University of Göteborg, Sweden. Galactosylceramidase activity was determined using a micromethod, ${ }^{78}$ slightly modified to meet the optimal conditions with this particular substrate. ${ }^{7}$ Each sample contained 5-9 $\mu \mathrm{g}$ enzyme protein, $2.5 \mathrm{nmol}$ substrate, $60 \mathrm{nmol}$ sodium taurocholate, $6 \mathrm{nmol}$ oleic acid in $20 \mu \mathrm{l}$ of $0.05 \mathrm{~mol} / \mathrm{l}, \mathrm{pH} 4.2$, acetate buffer, and was incubated at $37^{\circ} \mathrm{C}$ for two hours.

Control values were those of patients with neurological disorders or lysosomal diseases other than Krabbe's disease, randomly selected from analyses performed during the period 1984-90. The results in the four lateonset cases of Krabbe's disease are compared with those in 32 patients with the classic infantile form of the disease diagnosed in the laboratory during the same period.

\section{Case 1}

This girl is the second of two children born to Portuguese first cousins. Her mother has had two spontaneous abortions. She was born at term weighing $2.63 \mathrm{~kg}$ with a head circumference of $33 \mathrm{~cm}$. Apart from a febrile convulsion at 2 years 11 months, she had been well until the age of four years and nine months. There was no other relevant family history. Three months before admission to hospital the mother had noticed that the child was irritable, reluctant to leave her and had difficulty in seeing.

On admission at five years she had considerably decreased visual acuity, a divergent strabismus, normal fundoscopic examination, brisk deep tendon reflexes, bilateral Rossolimo responses but absent Babinski reflexes. She 
Figure Cerebral CT scan of Case 1 a) Without enhancement showing hypodensity around the lateral ventricles b) After contrast injection, showing enhancement of the splenium corpus callosum. posterior horns of the
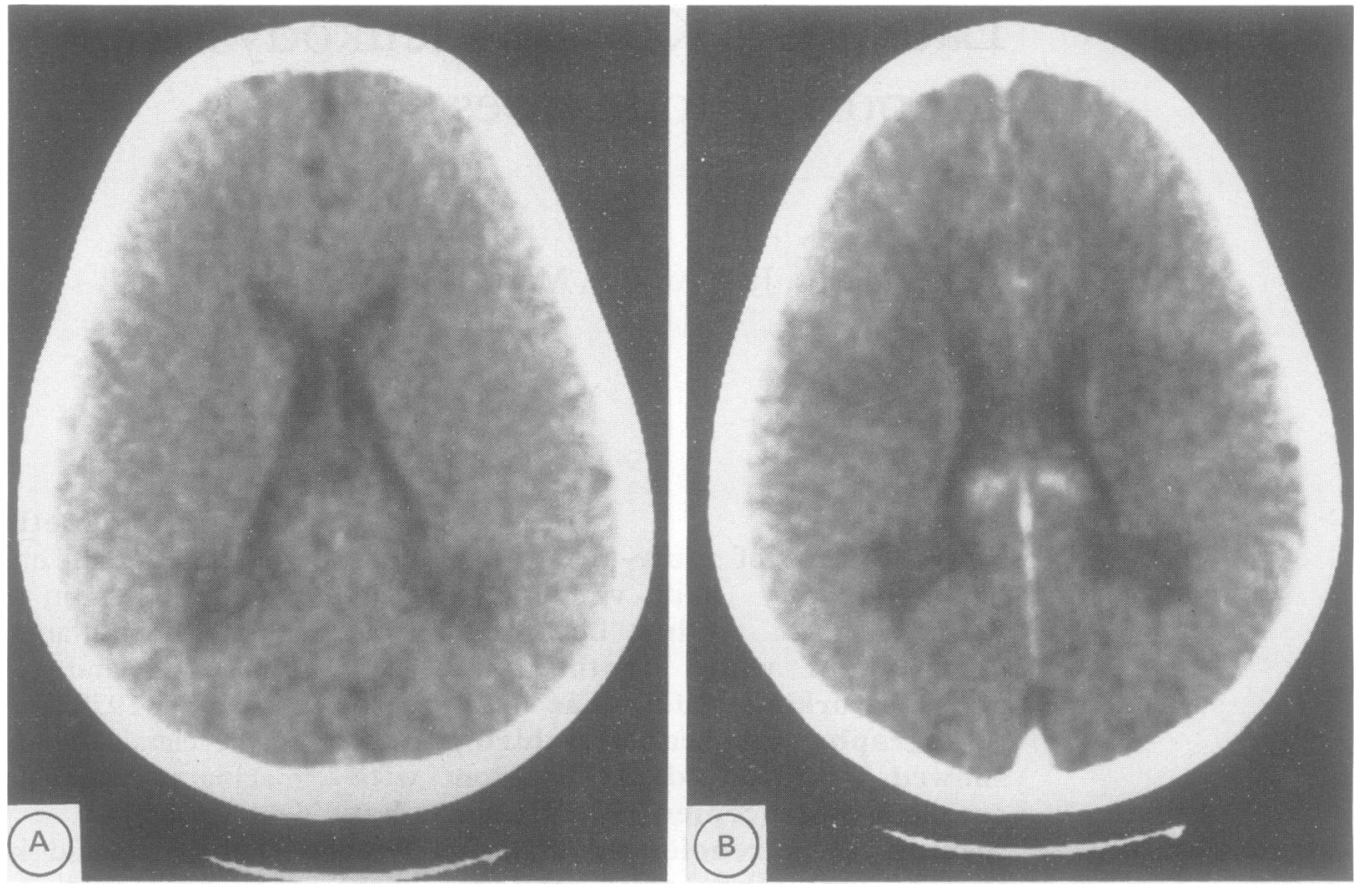

was ambulant and intellectually unimpaired, although very timid. The CT scan showed bilateral hypodensities of the white matter adjacent to the occipital horns of the lateral ventricles and contrast enhancement of the splenium, suggesting an adrenoleukodystrophy (fig). Long chain fatty acids were normal. Nerve conduction velocities and an electroretinogram were normal. Visual evoked potentials were markedly abnormal. CSF examination was normal.

Krabbe's leukodystrophy was diagnosed on the basis of a marked decrease in galactosylceramidase activity in peripheral blood leucocytes and skin fibroblasts. Enzyme activity measured in the mother's leucocytes showed an intermediate value consistent with a heterozygote state $^{9}$ (table).

At follow up at 5 years 6 months the patient was unable to walk, sit alone or speak. She was able to follow a light and had spastic tetraplegia.

\section{Case 2}

This girl was the last of five children whose parents are first cousins, once removed. She was born at 37 weeks gestation weighing

Table Galactosylceramidase activity in leucocytes and cultured skin fibroblasts

\begin{tabular}{llc}
\hline & $\begin{array}{l}\text { Leucocytes } \\
\text { (Activity expressed }\end{array}$ & $\begin{array}{c}\text { Skin fibroblasts } \\
\text { aicrokatal } / \text { kg protein) }\end{array}$ \\
\hline Case 1 & $0 \cdot 03$ & $0 \cdot 07$ \\
Case 2 & 0.05 & $0 \cdot 09$ \\
Case 3 & $0 \cdot 05$ & $0 \cdot 09$ \\
Case 4 & $\mathrm{ND}$ & $0 \cdot 06$ \\
Mother case 1 & $0 \cdot 19$ & $\mathrm{ND}$ \\
Mother cases 3 and 4 & $0 \cdot 31$ & $\mathrm{ND}$ \\
Father cases 3 and 4 & $0 \cdot 39$ & $\mathrm{ND}$ \\
Controls & $0 \cdot 70(0 \cdot 36)^{\star}$ & $0 \cdot 89(0 \cdot 55)^{\star}$ \\
Infantile Krabbe's disease & $(\mathrm{n}=100)$ & $(\mathrm{n}=20)$ \\
& $0 \cdot 04(0 \cdot 02)^{\star}$ & $0 \cdot 06(0 \cdot 02)^{\star}$ \\
Parents of patients with infantile & $(\mathrm{n}=24)$ & $(\mathrm{n}=19)$ \\
Krabbe's disease & $0 \cdot 41(0 \cdot 24)^{\star}$ & $\mathrm{ND}$ \\
& $(\mathrm{n}=44)$ & \\
\hline
\end{tabular}

$\mathrm{ND}=$ not determined; ${ }^{\star}=$ mean $(\mathrm{SD}) ; \mathrm{n}=$ number of individuals studied.
$2 \cdot 2 \mathrm{~kg}$ with a head circumference of $32 \mathrm{~cm}$ been well until the age of eight years. There was no other relevant family history.

Six months before admission she began to have difficulty walking and at school. Her parents also noted a change in behaviour with increasing aggression. Clinical examination at admission showed marked hypertonicity and hyperreflexia of the lower limbs and bilateral Babinski responses. The upper limbs showed minor dysdiadochokinesis and intention tremor. There were no other cerebellar signs.

Cerebral CT scan, visual and auditory evoked potentials and the electroretinogram were normal. The CSF showed a normal cell count with an elevated protein at $0.63 \mathrm{~g} / 1$ and an electrophoresis pattern consistent with a transudate. The electromyogram showed evidence of distal denervation and nerve conduction velocities were slowed, consistent with a peripheral neuropathy. A sural nerve tubular inclusions in the Schwann cell cytoplasm of myelinated fibres suggesting Krabbe's leukodystrophy. Also present in the non-myelinated fibres were pseudocrystalline inclusions similar to those described in Refsum disease. Krabbe's leukodystrophy was confirmed by the marked decrease in galactosylceramidase activity in the leucocytes and skin fibroblasts (table).

At 10 years and eight months her paediatrician indicated that she had stopped walking and there had been a marked intellectual deterioration.

Case 3

This girl was the third of four children born to non-consanguineous parents. She was born at term weighing $3.1 \mathrm{~kg}$. She was well until the age of five years when a decrease in visual acuity was noted. At six years and six months Apart from measles at eight months she had biopsy showed lightly packed myelin and 
she suffered a progressive left hemiplegia and a slow intellectual deterioration began.

On admission at 12 years, nine months she was wheelchair-bound with fixed contractures at the elbows, knees and hips and an inappropriately euphoric affect. She had marked facial grimacing and her movements were severely dystonic, with an athetoid component in the hands and feet. There was marked hypertonicity and hyperreflexia of all four limbs and bilateral Babinski responses. Her voice was almost unintelligible although some words were still comprehensible. She understood simple commands. She reacted to and followed a light, although at fundoscopy her discs were pale.

Nerve conduction studies and electromyogram were normal, as was the cerebrospinal fluid. The electroretinogram showed an increased latency on red light stimulation, indicative of a predominantly central retinal disturbance. The visual evoked potentials were abnormal but could not be explained by the retinal disturbance. The cerebral CT scan showed bilateral rounded hypodense areas in the upper parietal white matter and poor grey-white differentiation. A skin biopsy showed numerous nerve endings without specific inclusions, and an excess of glycogen either free or within mitochondria.

Krabbe's leukodystrophy was diagnosed by decreased activity of galactosylceramidase in the leucocytes and skin fibroblasts. The patient's parents showed galactosylceramidase leucocyte activity at an intermediate heterozygote level (table).

At follow up at 15 years and nine months the situation was unchanged with the patient remaining wheelchair-bound, euphoric and intellectually impaired.

\section{Case 4}

This young man was the older brother (by three years) of patient 3 . Following the diagnosis of Krabbe's disease in his sister he was seen in the outpatient clinic at the age of 16 years and five months.

From the age of five years he had had minor difficulty in walking, was easily fatigued, unable to run long distances, and had a decreased visual acuity that was uncorrected by glasses. Otherwise he continued to lead a normal life. Clinical examination revealed brisk tendon reflexes more pronounced in the lower limbs, ankle clonus and bilateral Babinski reflexes. The optic discs were pale but not atrophic. He was intellectually normal.

Cerebral CT scan demonstrated symmetric rounded hypodensities in the upper part of the centrum semi-ovale in the parietal regions. Galactosylceramidase activity in the leucocytes was considerably decreased, comparable with that of his sister. Follow up at the age of 19 years found that there had been no worsening of symptoms and, in contrast to his wheelchair-bound institutionalised sister, he works regularly as a baker.

\section{Discussion}

These four enzymatically confirmed cases fur- ther demonstrate the heterogeneity of the late onset form of Krabbe's globoid cell leukodystrophy. Patient 1 presented with visual problems and a CT scan suggesting an adrenoleukodystrophy, while patient 2 presented with a spastic diplegia, and some minor cerebellar signs. The contrast in the clinical condition of the siblings, patients 3 and 4 , is striking with the younger girl confined to a wheelchair and institutionalised while her brother continues a normal life, despite the comparable enzymatic abnormalities and CT images. Interestingly, neither patient has progressed clinically or radiologically for some years. Such discrepancies in the late-onset form, even within a family, pose difficulties for advising prognosis.

One clinical feature not previously evident in reported cases is the dystonic movements described in case 3. At admission seven years after onset of symptoms these movements were striking, involving mainly the face, hands and feet.

Consistent with a previous report ${ }^{10}$ the CSF protein in the three patients who had spinal fluid examination showed a normal protein concentration in two cases and a mildly elevated value in the other.

In only one of the patients (case 2) was there EMG evidence of a peripheral neuropathy and the peripheral nerve biopsy performed was interesting in that not only did it demonstrate inclusions classically described in biopsies of patients with Krabbe's leukodystrophy ${ }^{11}$ but also showed inclusions reminiscent of those seen in Refsum disease. ${ }^{12}$ The significance of this is not clear.

These four patients showed a severe deficiency of galactosylceramidase activity, with values less than $10 \%$ of the mean normal value. There was no significant difference between the levels of residual activities observed in infantile or late-onset patients which differs from the findings of Loonen et al. ${ }^{2}$ Similar results were also observed in cases 3 and 4, despite the clinical dissimilarity in these two siblings. The question of a pseudodeficiency in case 4 could be ruled out since both parents showed galactosylceramidase activities within the expected range for heterozygotes.

All four cases had had cerebral CT scans at varying times after the onset of symptoms, with the scan of patient 2 (six months after the onset of symptoms but not repeated) being normal. This has previously been described in the late-onset form. ${ }^{10}$ The CT scans of patients 3 and 4 show small identically distributed low density white matter changes despite the obvious clinical disparity. The most interesting of the CT scans is that of patient 1 , with its occipital hypodense areas and contrast enhancement of the corpus callosum, an appearance previously thought to be specific for adrenoleukodystrophy ${ }^{13}$ and not reported in Krabbe's leukodystrophy.

These clinical and investigative findings further contribute to the picture of late-onset Krabbe's leukodystrophy as a heterogeneous disease, despite enzyme activity comparable to the classic infantile variety. 
We thank Professor J Mikol for examining the nerve biopsy of patient 2.

1 Suzuki Y, Suzuki K. Globoid cell leukodystrophy (Krabbe's disease): Deficiency of galactocerebroside B-galactosidase. Proc Nat Acad Sci USA 1970;66:302.

2 Loonen MCB, Van Diggelen OP, Janse HC, Kleijer WJ, Arts WF. Late-Onset globoid cell leukodystrophy (Krabbe's leukodystrophy). Clinical and genetic delineation of two forms and their relation to the early-infantile form. Neuropediatrics 1985;16:137-42.

3 Böhles H, Schlenk R, Harzer K. Die unterschiedliche klinische Symptomatik der Globoidzell-Leukodystrophie (M. Krabbe) in einer Familie. Monatsschrift für Kinderheilkunde 1981;129:303-6.

4 Crome L, Hanefeld F, Patrick D, Wilson J. Late onset globoid cell leukodystrophy. Brain 1973;96:841-8.

5 Hanefeld F, Wilson J, Crome L. Die juvenile Form der Globoidzell-Leukodystrophie. Monatsschrift für KinderGloboidzell-Leukodystrophic

6 Vanier MT, Revol A, Fichet M. Sphingomyelinase activities of various human tissues in control subjects and in Niemann-Pick disease. Development and evaluation of a microprocedure. Clinica Chimica Acta 1980;106:257-67.
7 Mansson JE, Svennerholm L. The use of galactosylceramides. with uniform fatty acids as substrates in the diagnosis and carrier detection of Krabbe disease. Clinica Chimica Acta 1982;126:127-33.

8 Svennerholm L, Vanier MT, Hakansson G, Mansson JE. Use of leukocytes in diagnosis of Krabbe disease and detection of carriers. Clinica Chimica Acta 1981;112: 333-42.

9 Vanier MT, Svennerholm L, Mansson JE, Hakansson G Boué A, Lindsten J. Prenatal diagnosis of Krabbe disease and detection of carriers. Clinical Genetics 1981;20:79-89.

10 Vos AJM, Joosten EMG, Gabreëls-Festen AAWM Gabreëls FJM, Verspreet FAM. An atypical case of infantile globoid cell leukodystrophy. Neuropediatrics 1983;14:110-12.

11 Lyon G, Jardin L, Aicardi J. Etude au microscope electronique d'un nerf péripherique dans un cas de leukodystrophie de Krabbe. J Neurolog Sci 1971;12:263-74.

12 Fardeau M, Engel WK. Ultrastructural study of a peripheral nerve biopsy in Refsum's disease. J Neuropath Exper Neurol 1969

13 Aubourg P, Diebler C. Adrenoleukodystrophy-its diverse CT scan appearances and an evolutive or phenotypic variant: The leukodystrophy without adrenal insufficiency. Neuroradiology 1982;24:33-42. 